\title{
PENERAPAN DAN PELATIHAN E-COMMERCE PADA USAHA BENGKEL MITRA KARYA SITRA JEMBER
}

\section{TRAINING AND APPLICATION OF E-COMMERCE IN MITRA KARYA SITRA WORKSHOP JEMBER}

\author{
Rahma Rina Wijayanti ${ }^{\# 1}$, Oryza Ardhiarisca ${ }^{\# 2}$, Sumadi $^{\# 3}$, Rediyanto Putra ${ }^{\# 4}$ \\ \#1,2,3 Program Studi Akuntansi Sektor Publik, Politeknik Negeri Jember \\ Jl. Mastrip PO BOX 164 Jember, Jawa Timur \\ \#4 Jurusan Akuntansi, Universitas Negeri Surabaya \\ Jl. Ketintang No.2 Surabaya Jawa Timur \\ 1rahmarina11@gmail.com \\ ²oryza_risca@polije.ac.id \\ ${ }^{3}$ madidhea57@gmail.com \\ ${ }^{4}$ rediputra.rp@gmail.com
}

\begin{abstract}
Abstrak
Pengabdian kepada masyarakat yang akan dilakukan pada usaha Bengkel Mitra Karya Satria Jember dengan tujuan untuk meningkatkan daya saing. Pengabdian ini menggunakan skema Program Kemitraan Masyarakat (PKM). Masalah yang dihadapi oleh usaha bengkel ini adalah terdiri dari dua yaitu masalah kendala terkait kegiatan promosi yang masih sederhana. Solusi yang diberikan pada pengabdian ini melakukan pembuatan media pemasaran online untuk memperluas jangkauan promosi. Target yang ingin dicapai dari pengabdian ini adalah usaha bengkel Mitra Karya Satria Jember dapat memiliki peningkatan daya saing yang lebih baik, sehingga mampu menciptakan kesejahteraan yang lebih tinggi. Luaran dari pengabdian masyarakat adalah: satu produk blog pemasaran, satu artikel ilmiah yang dipublikasikan melalui jurnal nasional ber ISSN, dokumentasi video kegiatan, dan peningkatan keberdayaan mitra sesuai permaslahan yang dihadapi.
\end{abstract}

Kata Kunci: e-commerce, pemasaran, kesejahteraan

\section{Abstract}

Community service was carried out at Mitra Karya Satria Jember Workshop with the aim of increasing competitiveness. This service uses the Community Partnership Program (PKM) scheme. The problem faced by this workshop business consists of two problems, namely constraints related to promotional activities that are still simple. The solution provided in this service is creating online marketing media to expand the reach of promotions. The target to be achieved from this dedication is that Mitra Karya Satria Jember's workshop can have improved competitiveness, so as to create higher welfare. The outputs of community service are: a marketing blog product, a scientific article published through an ISSN national journal, video documentation of activities, and enhancing the empowerment of partners in accordance with the issues at hand.

Keywords : e-commerce, marketing, walfare

\section{PENDAHULUAN}

Usaha bengkel Mitra Karya Satria adalah usaha bengkel yang berlokasi di Jl. Mawar No. 65 Jember. Usaha bengkel ini setiap hari beroperasi dari jam 08.00 sampai 17.00 WIB. Usaha ini didirikan sejak tahun 2001 oleh Bapak Bambang Sarwono yaitu pemilik usaha. Bapak Sarwono merupakan seseorang yang pernah bekerja di PT. Mitsubishi sebagai mekanik dan service advisor dari tahun 1990 sampai 1999. Usaha bengkel ini didirikan dengan modal awal 10 juta rupiah.
Usaha bengkel ini menerima beberapa macam jenis jasa perawatan kendaraan seperti servis ringan dan berat, understeal, engine overall, servis AC, dan pengelasan. Usaha bengkel ini dalam kegiatan operasionalnya dijalankan oleh 4 orang karyawan yang memiliki tanggung jawab dan tugas masing-masing. Usaha bengkel ini dalam memberikan pelayanan kepada konsumen juga tidak terbatas pada lokasi usaha saja, namun juga dilakukan dengan cara mendatangi lokasi konsumen yang membutuhkan jasa dari usaha bengkel ini. 
Usaha bengkel ini selama perjalanannya pernah bermitra dengan dua perusahaan di Jember dalam hal perawatan kendaraan yaitu PT. HM. Sampoerna dan PT. Bank Mandiri Persero cab. Jember. Kerja sama tersebut dijalin dari tahun 2005 dengan jumlah mobil yang dirawat pada saat terjalin kerja sama tersebut adalah sebanyak 15 unit kendaraan untuk tiap perusahaan. Namun, proses kerja sama tersebut pada akhirnya berhenti karena pada beberapa tahun terakhir ini perusahaanperusahaan tersebut lebih memilih untuk menggunakan jasa sewa kendaraan untuk kendaraan operasional perusahaan, sehingga biaya perawatan pun tidak ada. Meskipun demikian, usaha bengkel ini pada saat ini sudah memiliki pelanggan setia sekitar $50-100$ orang yang selalu melakukan perawatan kendaraan.

Usaha bengkel Mitra Karya Satria juga menjadi tempat untuk menjadi magang siswa Sekolah Menengah Kejuruan (SMK) di Jember. Kegiatan magang yang dilakukan selama 3 bulan dalam setahun. Ada empat Sekolah Menengah Kejuruan (SMK) yang menjadikan usaha bengkel ini sebagai lokasi magang yaitu SMK Nurul Islam Jember, SMK PGRI Jember, SMK Balung, dan SMK Berdikari Jember.

Usaha bengkel Mitra Karya Satria pada saat ini menjelaskan bahwa mengalami kendala terkait proses promosi, lokasi, dan sarana prasarana yang ada. Usaha bengkel ini mengalami kesulitan untuk melakukan penambahan jumlah pelanggan karena cara promosi yang digunakan masih sangat tradisional yaitu mouth to mouth. Cara ini dianggap paling mudah karena tidak memerlukan banyak biaya untuk dilakukan, namun akibatnya adalah masih banyak orang yang tidak mengetahui mengenai eksistensi usaha bengkel tersebut. Hal ini diperparah dengan tidak adanya tulisan, banner, atau sejenisnya di lokasi usaha. Dengan demikian, setiap orang yang melewati daerah tersebut kurang memahami bahwa lokasi tersebut adalah bengkel.

Penjelasan mengani adanya dua keterbatasan pada usaha bengkel Mitra Karya Satria di atas menunjukkan bahwa proses bisnis yang terjadi berjalan tidak maksimal. Hal ini dikarenakan kendala-kendala yang ada tersebut dapat menyebabkan daya saing yang dimiliki oleh usaha bengkel ini menjadi berkurang dan tidak maksimal. Oleh karena itu, pengabdian ini dilakukan untuk memberikan solusi atas masalah yang dihadapi oleh usaha bengkel Mitra Karya Satria. Tujuannya adalah agar dapat membantu memecahkan masalah yang ada dan dapat meningkatkan kemampuan bersaing usaha bengkel Mitra Karya Satria dalam proses bisnis.

\section{TARGET DAN LUARAN}

Kegiatan pengabdian masyarakan akan dilakukan di Bengkel Mitra Karya Satria Jember. Kegiatan pengabdian ini bertujuan untuk memberikan solusi atas permasalahan-permasalahan yang dihadapi oleh Bengkel Mitra Karya Satria. Solusi dari permasalahan yang dihadapi oleh mitra ini merupakan praktik penerapan konsep marketing mix dari ilmu manajemen pemasaran. Bentuk penerapan ilmu manajemen pemasaran pada pengabdian ini berfokus pada konsep bauran pemasaran. Bauran pemasaran menjadi suatu bentuk cara entitas bisnis untuk menyampaikan keunggulan kompetitif yang dimiliki. Bauran pemasaran terdiri dari 4P yaitu Product, Price, Place, Promotion [1]. Pengabdian ini akan memberikan solusi permasalahan pada aspek product, place, dan promotion. Pengabdian ini memberikan solusi permasalahan terkait aspek promotion adalah pembuatan media pemasaran online yang dapat menjadi sarana promosi usaha dari mitra.

Bengkel Mitra Karya Satria saat ini belum melakukan pemasaran secara agresif. Konsumen yang berdatangan hanya mengetahui informasi dari mulut ke mulut atau secara kebetulan membutuhkan jasa bengkel saat berada di daerah Bengkel Mitra Karya Satria. Oleh karena itu, perlu dilakukan peningkatan dalam hal pemasaran.

Pemasaran memiliki tujuan untuk menginformasikan, membujuk serta mengingatkan pelanggan sasaran tentang perusahaan dan produk atau jasa. Media dibutuhkan dalam kegiatan promosi. Adapun media atau alat promosi yang dapat digunakan yaitu: periklanan, promosi penjualan, hubungan masyarakat dan publisitas, penjualan personal, dan pemasaran langsung. Adapun jenis saluran utama dalam pemasaran langsung yaitu: penjualan tatap muka, pemasaran direct mail, pemasaran melalui katalog, telemarketing, pemasaran melalui televisi, pemasaran melalui kios, dan pemasaran melalui saluran online.

Pada program pengabdian masyarakat ini memilih penggunaan pemasaran secara online. Hal ini dilatarbelakangi oleh rendahnya biaya yang dikeluarkan, jangkauan pemasaran yang lebih luas, serta masyarakat dapat dengan mudah mengetahui informasi produk dan layanan yang dimiliki oleh Bengkel Mitra Karya Satria.

Saluran online (e-marketing) merupakan saluran yang dapat dijangkau menggunakan komputer dan modem. Komputer dapat menjangkau beragam layanan online melalui penggunaan modem yang dapat menghubungkan komputer dengan jalur telepon. E-marketing merupakan suatu proses pemasaran yang menggunakan internet sehingga diperoleh informasi mengenai produk, dapat 
melakukan transaksi jual beli dan dapat mempromosikan produk yang sudah dikonsumsi [2].

Adapun media pemasaran yang akan digunakan dalam pengabdian masyarakat ini adalah dengan memanfaatkan teknologi informasi yaitu berupa pembuatan blog serta pembuatan akun di media sosial. Blog dan akun media sosial ini berisi mengenai:

a) Profil dari Bengkel Mitra Karya Satria profil dari Bengkel Mitra Karya Satria berisi mengenai nama pemilik bengkel dan nama pegawai dari bengkel tersebut serta waktu berdirinya bengkel. Pencantuman waktu berdirinya bengkel dapat menjadi pertimbangan bagi konsumen mengenai keahlian suatu bengkel dalam memperbaiki kendaraan. Semakin lama suatu bengkel berdiri, maka semakin banyak permasalahan perbengkelan yang telah dihadapi sehingga semakin ahli suatu bengkel dalam memperbaiki kendaraan. Begitu juga dengan pencantuman pegawai dapat memberikan informasi mengenai keahlian dari setiap pegawai yang ada.

b) Jam kerja bengkel

blog atau akun media sosial juga berisi jam kerja dari bengkel mitra karya satria sehingga ketika ada masyarakat atau calon konsumen yang membutuhkan sudah mengetahui kapan waktu buka kerja bengkel.

c) Layanan atau jasa yang diberikan

blog atau akun media sosial juga berisi mengenai layanan atau jasa yang diberikan. Hal ini bertujuan agar masyarakat atau calon konsumen yang membuka blog tersebut dapat dengan mudah mengenai apa-apa saja yang menjadi layanan dari bengkel tersebut. Misalnya: servis rutin, ganti oli, tambal ban, penambahan angin, pengecatan kendaraan dan lain sebagainya.

Adanya sarana media pemasaran melalui blog dan akun media sosial ini akan memberikan peluang bagi mitra untuk mengembangkan jumlah pelanggan. Hal ini dikarenakan media pemasaran online tentunya akan menjadi pertimbangan bagi calon konsumen untuk dapat menggunakan pelayanan jasa yang ditawarkan oleh Bengkel Mitra Karya Satria.

\section{METODE PELAKSANAAN}

Kegiatan pengabdian ini akan dilakukan pada usaha bengkel "Mitra Karya Satria Jember". Lokasi mitra berada di Jl. Mawar 65 Jember. Pengabdian ini akan ditujukan untuk menerapkan konsep marketing mix dari ilmu manajemen pemasaran. Tujuannya adalah untuk dapat meningkatkan daya saing dari mitra, sehingga dapat meningkatkan kesejahteraan mitra. Pelaksanaan kegiatan pengabdian masyarakat ini dilakukan dengan beberapa metode. Penjelasan secara lebih mendalam terkait sistematika metode kegiatan pengabdian ini adalah sebagai berikut:

1. Survei Lapangan

Metode pertama yang dilakukan adalah survei lapangan. Tujuan dari metode ini adalah mendapatkan informasi dan pemahaman lebih dalam mengenai kondisi dan situasi yang ada di mitra

2. Pembuatan Media Pemasaran Online Metode selanjutnya adalah melakukan perancangan dari media pemasaran online. Media pemasaran online yang akan digunakan pada pengabdian ini adalah blog dan akun media sosial. Tujuannya adalah agar usaha dari mitra dapat lebih dikenal oleh publik, sehingga semakin membuka peluang perluasan pangsa pasar.

3. Assessment

Metode yang terkahir adalah metode assessment. Metode ini melakukan suatu bentuk penilaian mengenai hasil dari pengabdian yang telah dilakukan. Tujuannya adalah untuk mencari kekurangan yang masih bisa diperbaiki untuk dilakukan pada program pengabdian selanjutnya.

\section{HASIL DAN PEMBAHASAN}

3.1. Hasil Pembuatan Blog Pemasaran

Pengabdian ini membuat blog pemasaran dengan bantuan wordpress.com. blog yang dibuat untuk mitra ini adalah versi free sehingga ada kata wordpress pada laman mitra. Versi free ini digunakan dengan tujuan agar mitra tidak perlu mengeluarkan biaya domain untuk setiap tahun nya. Media e-commerce blog ini adalah masih versi sederhana karena belum terlalu banyak konten yang dimasukkan kedalamnya. Pemasukan konten ke dalam website ini dapat dilakukan secara bertahap. Blog e-commerce mitra ini dapat diakses pada alamat

https://mitrakaryasatriajember.wordpress.com/.

Berikut disajikan tampilan blog e-commerce dari bengkel Mitra Karya Satria Jember. 


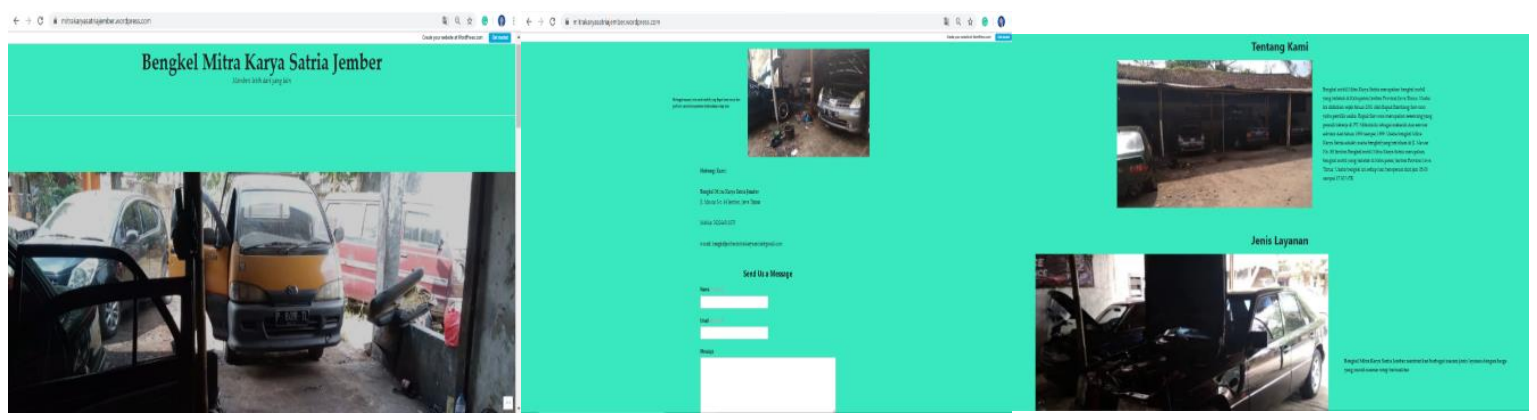

Gambar 1. Tampilan blog e-commerce mitra

\subsection{Proses Pelatihan Blog Pemasaran}

Blog e-commerce yang telah disediakan untuk mitra kemudian digunakan sebagai bahan untuk pelatihan penggunaan media e-commerce tersebut kepada mitra. Pelatihan ini dilakukan agar mitra bisa menjalankan media e-commerce yang

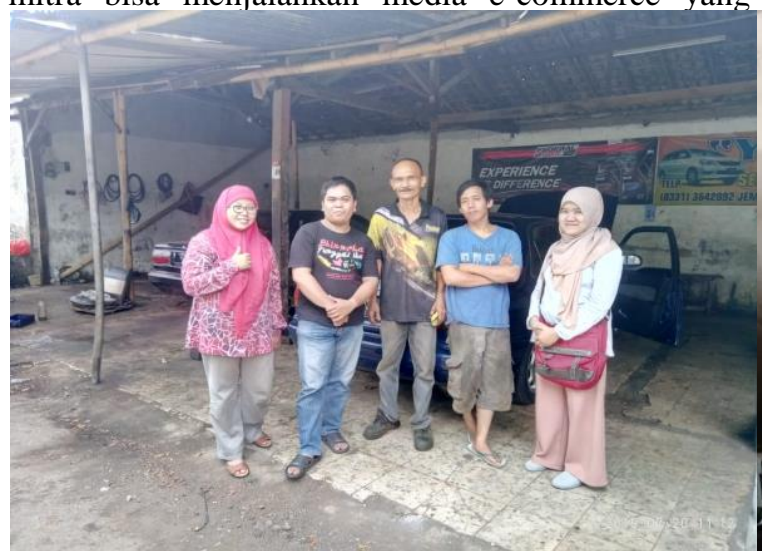

Gambar 2. Pelatihan blog e-commerce

IV.KESIMPULAN

Hasil pengabdian ini memberikan suatu manfaat yang dirasakan baik oleh mitra untuk pengembangan usahanya di masa yang akan datang. Mitra merasa terbantu dengan adanya program pengabdian ini karena program pengabdian ini dirasa dapat menyelesaikan masalah yang dihadapi terkait luas lingkup pemasaran yang dimiliki. Usaha bengkel Mitra Karya Satria Jember juga berharap agar kegiatan pengabdian ini bisa berlanjut di masa yang akan datang untuk membantu menyelesaikan masalah yang dihadapi lainnya.

\section{UCAPAN TERIMAKASIH}

Ucapan terimakasih tidak lupa disampaikan kepada Politeknik Negeri Jember yang telah memberikan kesempatan bagi tim pelaksana pengabdian untuk melakukan pengabdian dengan dimilikinya, sehingga dapat bermanfaat untuk keberlanjutan dan pengembangan usaha yang dimiliki. Gambar 2 berikut menyajikan mengenai dokumentasi kegiatan pelatihan yang telah dilakukan.

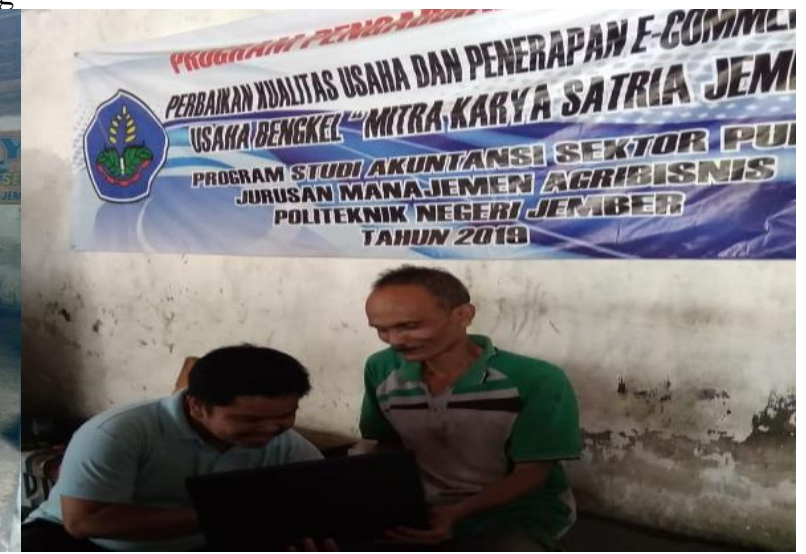

menggunakan dana yang berasal dari PNBP Politeknik Negeri Jember tahun 2019. Terima kasih juga disampaikan kepada Politeknik Negeri Jember karena telah membantu proses administrasi terkait pelaksanaan proses pengabdian ini. Ucapan terima kasih selanjutnya diberikan kepada mitra pengabdian yaitu usaha bengkel Mitra Karya Satria Jember yang telah berkenan untuk menjadi mitra pada pengabdian ini.

\section{DAFTAR PUSTAKA}

[1] Ferrel, L. 2008. Manajemen Pemasaran: Pendekatan Praktis. Edisi Pertama. Cetakan Pertama. Yogyakarta: Graham Ilmu.

[2] Mardiani, I. E. \& Imanuel, O. J. 2013. Analisis Keputusan Pembelian Konsumen Melalui Media Online (E-Marketing). Jurnal Ekonomi Vol. 4. No. 2. November 2013. 